\section{ERRORCALC: A BASIC microcomputer program to calculate psychophysical error measures for variable block sizes}

\section{MARC A. PIZZIMENTI, DANIEL J. WEEKS, and TIMOTHY D. LEE \\ McMaster University, Hamilton, Ontario, Canada}

Researchers who employ the method of constant stimuli often run a large number of trials to assess a treatment effect. The result, generally, is two estimates of error: (1) the within-trial error for a particular treatment (i.e., the difference magnitude between the criterion or goal and the subject's estimate of that goal), and (2) the between-trial deviations for a particular number of these difference magnitudes. Behaviorally, these estimates of performance error indicate measures of accuracy and consistency, respectively.

In a typical motor learning study, for example, if a subject completes 30 trials in attempting to achieve some criterion-referenced goal, each performance error score (i.e., the performance score-the criterion goal) may be grouped into "blocks" of, perhaps, 5 trials each. For each of the six blocks, then, estimates of performance accuracy and consistency may be assessed and subjected to statistical analyses. The traditional measure of performance accuracy over a block of trials has been calculated as the mean of the algebraic (signed) error scores on each trial, termed constant error (CE). Performance consistency over the same block of trials is the standard deviation of $\mathrm{CE}$, termed variable error (VE). These measures have by no means, however, been employed exclusively.

Based upon statistical grounds, Schutz (1977) argued for the use of the absolute value of a subject's constant error (i.e., absolute constant error, or $|\mathrm{CE}|)$ when averaging over a group of individuals, as the more appropriate measure of performance accuracy. Composite error measures that reflect both performance accuracy and consistency have also been popular: (1) absolute error $(\mathrm{AE})$ is the mean of the unsigned performance error scores, and (2) total error (E) is a composite error measure that combines equally the contribution of accuracy and consistency (where $E^{2}=C E^{2}+V E^{2}$ ).

The absence of a common theoretical rationale for reporting specific error measures, however, has made cross-study comparisons difficult. In the motor behavior research area, for instance, it has been suggested that

The authors' mailing address is: School of Physical Education and Athletics, McMaster University, Hamilton, Ontario L8S 4K1, Canada.
Table 1

Sample Output for the Five Error Measures Over a Block of 5 Trials

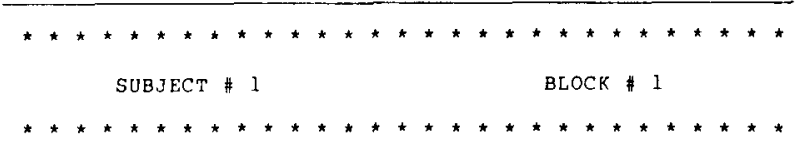

ENTER ERROR SCORES

1) ? -35

2) ? 48

3) ? -27

4) ? -46

5) ? 22

ANY CHANGES TYPE 'ERROR', ELSE PRESS 〈RETURN 〉

$\begin{array}{lc}\text { CONSTANT ERROR = } & -7.6 \\ \text { ABSOLUTE CONSTANT ERROR }= & 7.6 \\ \text { VARIABLE ERROR = } & 36.246 \\ \text { TOTAL ERROR = } & 37.034 \\ \text { ABSOLUTE ERROR = } & 35.6\end{array}$

PRESS ANY KEY TO CONTINUE

multiple dependent measures should be reported to facilitate more direct comparisons of research (Battig, 1977; Ho \& Shea, 1979). The software described in this paper is designed to permit a researcher to calculate all five error measures simultaneously, using a BASIC microcomputer program.

Input. The program allows for two types of data input: either (1) the criterion goal and the raw trial performance scores for a block of trials, or (2) the previously determined trial error scores. Variable trial block sizes up to $n=25$ may be specified.

Output. Presentation of the five error measure calculations for a block of trials is provided, following the conclusion of data entry. A sample output is illustrated in Table 1. In addition, a summary of error measure calculations over all trial blocks for a subject is also provided.

Program Language. Versions of the ERRORCALC program have been devised on DOS for both the Radio Shack TRS 80 (Models II and III) and the Apple II (and compatible) microcomputers (32K minimum).

Availability. A listing and sample run of ERRORCALC is available upon request from Timothy Lee, School of Physical Education and Athletics, McMaster University, Hamilton, Ontario L8S 4K1, Canada. Please specify the program language version requested. 


\section{REFERENCES}

Battio, W. F. (1977). Reaction to Schutz. In D. Mood (Ed.), The measurement of change in physical education. Boulder, $\mathrm{CO}$ : University of Colorado Press.

Ho, L., \& SHEA, J. B. (1979). Orienting task specificity in incidental motor learning. Journal of Motor Behavior, 11, 135-140.
Schutz, R. (1977). Absolute, constant and variable error: Problems and solutions. In D. Mood (Ed.), The measurement of change in physical education. Boulder, CO: University of Colorado Press.

(Revision accepted for publication January 23, 1984.) 